\title{
Suppression of lactation and acceleration of involution in the bovine mammary gland by a selective serotonin reuptake inhibitor
}

\author{
L L Hernandez, J L Collier ${ }^{2}$, A J Vomachka ${ }^{1}$, R J Collier ${ }^{2}$ and N D Horseman \\ Department of Molecular and Cellular Physiology, University of Cincinnati, Cincinnati, Ohio 45208, USA \\ ${ }^{1}$ Department of Biology, Arcadia University, Glenside, Pennsylvania 19038, USA \\ ${ }^{2}$ Department of Animal Sciences, University of Arizona, Tucson, Arizona 85721, USA \\ (Correspondence should be addressed to N D Horseman; Email: nelson.horseman@uc.edu)
}

\begin{abstract}
Serotonin $(5-\mathrm{HT})$ is a homeostatic regulator of lactation. Selective 5-HT reuptake inhibitors (SSRI) are commonly prescribed pharmaceuticals that inhibit activity of the 5-HT reuptake transporter, increasing cellular exposure to 5-HT. Use of SSRIs has been shown to alter lactation performance in humans and 5-HT has been shown to reduce milk yield in cattle. However, it has not been determined how SSRI treatments affect the bovine mammary gland. We evaluated the effects of SSRI (fluoxetine (FLX)) administration on tight junctions (TJs) and milk protein gene expression in a lactogenic culture model, using primary bovine mammary epithelial cells (pBMEC). Additionally, we evaluated the effects of intramammary infusions of FLX and 5-hydroxytryptophan on milk production and $\mathrm{TJ}$ status in multiparous Holstein cows at dry-off. Treatment of pBMEC cultured on
\end{abstract}

permeable membranes disrupted $\mathrm{TJ}$ s, as measured by transepithelial resistance and immunostaining for zona occludens 1. Correspondingly, treatment of '3D', collagenembedded lactogenic cultures of pBMEC with FLX suppressed milk protein gene expression $(\alpha$-lactalbumin and $\beta$-casein) in a concentration-dependent manner. Finally, intramammary treatment of Holstein cows with FLX resulted in an accelerated rate of milk decline. Additionally, TJ permeability increased in FLX-treated animals, as measured by plasma lactose and milk $\mathrm{Na}^{+}$and $\mathrm{K}^{+}$levels. Results of these experiments imply that SSRI administration accelerates the rate of mammary gland involution through disassembly of TJs and inhibition of milk protein gene expression in vitro and in vivo, leading to reduction of milk yield.

Journal of Endocrinology (2011) 209, 45-54

\section{Introduction}

Mammary gland involution is a complex and critical process that the gland undergoes at the cessation of its lactation cycle, or when demand for milk decreases. The process in laboratory rodents is associated with a high level of epithelial cell apoptosis and extensive remodeling of the gland (Stein et al. 2007). However, the morphological changes at involution in dairy animals (cattle, goats and sheep) are less pronounced than in rodents. The changes in humans are intermediate between rodents and dairy animals (Capuco \& Akers 1999). Involution in dairy animals is characterized by a low and relatively continuous rate of epithelial cell turnover and mammary gland morphological maintenance, rather than a large-scale tissue regression process as seen in rodents (Capuco \& Akers 1999). The morphological changes that occur in the mammary gland of dairy animals at involution largely reflect a change in the secretory state of the gland, rather than the tissue remodeling process (Capuco \& Akers 1999). Apparent differences among species partially reflect whether involution is concurrent with pregnancy under typical experimental conditions. Involution and mammary cell turnover is a critical process in the cycle of the mammary gland in dairy animals, which must undergo a dry period in order to avoid losses in milk production in their subsequent lactation cycle (Collier et al. 2004).

Intramammary infections contracted during the dry period have been associated with increased rates of infection during the subsequent lactation, and therefore large losses in milk production (Eberhart 1986). Currently, mastitis is the costliest disease in the dairy industry, resulting in losses over $\$ 2$ billion a year in the United States (Rainard 2005). Furthermore, mastitis often occurs in lactating women during periods of insufficient drainage, rapid weaning, oversupply of milk, pressure on the breast, blocked ducts and lengthy intervals between feedings (Betzold 2007). The incidence of mastitis increases significantly during periods of milk stasis both in dairy animals and in humans (Oliver \& Sordillo 1988, Betzold 2007). In fact, of all enterobacterial mastitis infections, $52 \cdot 6 \%$ arise in glands previously infected during the dry period in dairy animals (Bradley \& Green 2000). Furthermore, dairy animals producing more milk at the time they end the dry 
period, as well as individual quarters/glands that are producing more milk, are more susceptible to intramammary infections (Oliver \& Smith 1982). Mastitis ranges from 2 to $33 \%$ of lactating women who are exposed to extended intervals of milk stasis (Betzold 2007).

Acceleration of involution would be important for protection against mastitis in humans during weaning and in dairy animals during the dry period. Currently, dairy animals are subjected to frequent milking intervals followed by abrupt cessation of milking in combination with antibiotic treatment, and in some cases feed restriction, to reduce milk secretion and initiate the involution period (Dingwell et al. 2001). Cessation of milk secretion typically takes 3 days, and currently $16 \%$ of quarters become infected with new intramammary infections during this 3-day interval (Dingwell et al. 2002). Lactating women are currently not provided with a procedure to reduce milk secretion upon cessation of breastfeeding, and are at higher risk of mastitis due to milk stasis (Michie et al. 2003).

An intrinsic serotonin (5-HT) system within the mammary gland has been identified as a homeostatic regulator of lactation (Matsuda et al. 2004, Stull et al. 2007, Hernandez et al. 2008, Pai \& Horseman 2008). The mammary glands of mice, cattle and humans express unique patterns of 5-HT receptors that vary among the species (Hernandez et al. 2009, Pai et al. 2009). The mammary glands of each species express the rate-limiting enzyme, tryptophan hydroxylase 1 (TPH1), necessary for 5-HT synthesis, and 5-HT reuptake transporter (SERT), which is responsible for the reuptake of 5-HT into the cell and its subsequent degradation into its inactive metabolite (Matsuda et al. 2004, Stull et al. 2007, Hernandez et al. 2009, Marshall et al. 2010). 5-HT is synthesized via a two-step enzymatic pathway from the amino acid L-tryptophan, with 5-hydroxytryptophan (5-HTP) as the intermediate substrate (Wang et al. 2002). 5-HT accelerates mammary gland involution in response to milk stasis by acting on the $5-\mathrm{HT}_{7}$ receptor to disrupt tight junctions (TJs), as evidenced by decreases in transepithelial electrical resistance (TEER) and the TJ proteins (Stull et al. 2007, Pai \& Horseman 2008). Culturing of mammary epithelial cells on permeable membranes (Transwell) to monitor TJ permeability has proven to be reliable for mammary epithelial cells (Stull et al. 2007, Marshall et al. 2009). Transiently, 5-HT acts to decrease TJ permeability through protein kinase A, and sustained 5-HT causes an increase in permeability by activation of p38 MAP kinase (Pai \& Horseman 2008).

The class of pharmaceutical agents belonging to the 5-HT-selective reuptake inhibitor (SSRI) family target the membrane protein SERT (SLC6A4), located on neurons at pre-synaptic terminals, axons, dendrites, neuronal cell bodies and on other cells such as platelets and mammary epithelium. By inhibiting SERT, the SSRIs increase the cellular exposure to 5-HT, and thereby the activation of 5-HT signaling pathways. SSR Is are among the most widely prescribed classes of drugs in the United States, with 232.7 million prescriptions being dispensed in 2007 (Thomas \& Ellingrod 2009).
Because of their specificity for SERT, and their kinetic rather than stoichiometric mode of action, SSRIs are well tolerated in patients and the potential for toxicity in overdose is very low (Barbey \& Roose 1998).

It was recently shown that there is a delay in secretory activation in mothers who take SSRIs, and initiation of local involution in mice with fluoxetine (FLX) pellets implanted in the lactating mammary gland (Marshall et al. 2010). The objectives of the current experiments were to 1) determine the effects of SSRI treatment on TJ permeability in bovine mammary epithelial cells (BMEC) in vitro, 2) determine the effects of SSRI treatment on milk protein gene expression in lactogenic primary BMEC (pBMEC) in vitro and 3) determine the effects of FLX and 5-HTP intramammary infusions on TJ status and milk secretion in Holstein dairy cows.

\section{Materials and Methods}

\section{Cell culture studies}

To elucidate the effects of FLX (Sigma) on TJ and milk protein mRNA expression, experiments were designed using pBMEC. Tissue dissociation and $\mathrm{pBMEC}$ cell isolation were performed as previously described (McGrath 1987, Hernandez et al. 2008).

For TJ experiments, pBMEC were plated on rat-tail collagen-coated dishes until they reached confluency ( $\sim 6$ days) in growth media consisting of DMEM:F12 (50:50; Invitrogen), 10\% fetal bovine serum (Hyclone, Logan, UT, USA), $10 \mu \mathrm{g} / \mathrm{ml}$ insulin (Sigma), $25 \mathrm{ng} / \mathrm{ml}$ epidermal growth factor (EGF; Sigma), $10 \mathrm{ng} / \mathrm{ml}$ hydrocortisone (Sigma), $10 \mathrm{mM}$ sodium acetate (Sigma) and 1:100 antibiotic/antimycotic (Invitrogen). At confluency, pBMEC underwent a differential trypsinization, in which cells were treated for $2 \mathrm{~min}$ with trypsin to remove non-epithelial cells, and then treated with trypsin for an additional 8 min to detach epithelial cells, which were plated on uncoated dishes. Upon reaching confluency on non-collagen-coated dishes, $\mathrm{pBMEC}$ were trypsinized, counted and then seeded at $10^{5} \mathrm{cells} / \mathrm{cm}^{2}$ onto $0.4 \mu \mathrm{M}$ Transwell polyester membrane supports in 12-well plates (Corning, Corning, NY, USA). Cells were fed once daily in the basal and apical chambers until plateau resistance $\left(\sim 2500 \Omega \mathrm{cm}^{2}\right)$ was achieved $(\sim 6$ days). TEER $\left(\Omega \mathrm{cm}^{2}\right)$ was measured daily prior to feeding the cells. At this time, cells were changed to medium with their respective treatments (40, 100, 200 and $400 \mu \mathrm{M} \mathrm{FLX)} \mathrm{in} \mathrm{the} \mathrm{apical}$ chamber only for $72 \mathrm{~h}$, while the basolateral chamber received media without FLX. Results are expressed as a percent change in TEER relative to the control.

For lactogenic experiments, pBMEC were cultured in 3D collagen gels (McGrath 1987, Hernandez et al. 2008, 2009, Stiening et al. 2008). Epithelial cells in the form of organoid clumps consisting of ductal and alveolar cells were isolated from four multiparous, non-lactating ( $~ 30$ days dry) 
Holstein cows as previously described (McGrath 1987, Hernandez et al. 2008, 2009). Preparation of type I collagen was performed, as previously described (McGrath 1987, Hernandez et al. 2008, 2009). Briefly, pBMEC were thawed, re-suspended in DMEM:F12, mixed with neutralized type I collagen at $4-6 \times 10^{5}$ organoids $/ \mathrm{ml}$ of collagen mixture and cultured in 24-well plates, as previously described (Hernandez et al. 2008, 2009). The average DNA content of one vial of pBMEC was $486 \cdot 7 \pm 84 \cdot 91 \mu \mathrm{g} / \mathrm{ml}$ (mean \pm s.D.), providing sufficient cells for 72 wells in an average of $\sim 6.8 \mu \mathrm{g} \mathrm{DNA} /$ well. $\mathrm{pBMEC}$ were grown for 8 days in serum-free media $(10 \mu \mathrm{g} / \mathrm{ml}$ insulin, Sigma and $25 \mathrm{ng} / \mathrm{ml}$ EGF, Sigma) and then treated with a lactogenic hormone complex $(500 \mu \mathrm{g} / \mathrm{ml}$ insulin; Sigma), $100 \mathrm{ng} / \mathrm{ml}$ prolactin (NIDDK, Bethesda, MA, USA) and $10 \mathrm{ng} / \mathrm{ml}$ hydrocortisone (Sigma), and gel release, with and without FLX treatments $(5,10,20,40,400 \mu \mathrm{M}$, and $1.4 \mathrm{mM})$. Medium was exchanged every $48 \mathrm{~h}$ and FLX treatments were initiated at the time of lactogenic treatment of pBMEC and continued for $48 \mathrm{~h}$.

\section{In vivo study}

The study was conducted from 21 to 24 December, 2009 on a 10000 cow commercial dairy in Stanfield, AZ, USA. The University of Arizona's Institute of Animal Care and Use Committee approved all protocols and use of animals in the current study. Prior to the start of the study, all cows were being milked three times daily. Cows were fed three times daily and feed was pushed up every half hour. Diet analysis was conducted by Chandler Analytical Laboratories (Chandler, AZ, USA; Table 1). All cows were housed in open dry-lot facilities with Saudi style shades, and pens were identical in size, location and design and all dairy cows in the experiment were in late lactation, healthy and producing at least $20 \mathrm{~kg}$ of milk/day when assigned to the study. A total of 30 multiparous cows were identified and randomly assigned to once-a-day milking in the hospital barn using Dairy Herd Improvement Association (DHIA) test equipment meters followed by one of the two treatments for 3 days and then sealing the teats on day 4 . The control (CTRL) group received intramammary infusions of the carrier (sterile water mixed with sterile mineral oil at 9:1 ratio) followed by ToDAY (cephapirin sodium; Boehringer Ingelheim, St Joseph, MO, USA) in each quarter for 2 days, and on the third day, the carrier was followed by Quartermaster (Pfizer, New York, NY, USA) and Orbaseal (Pfizer). The FLX group received $5 \mathrm{mg}$ of FLX in the carrier followed by Today in each quarter for 2 days and followed by Quartermaster and Orbaseal on the third day. The 5-HTP group received $5 \mathrm{mg}$ of 5 -HTP in the carrier followed by Today in each quarter for 2 days followed by Quartermaster and Orbaseal on the third day. Blood samples were obtained by tail venipuncture on days 2 , 3 and 4 after initiation of treatments to measure plasma FLX concentrations. All milk samples were visually inspected for clumping immediately after collection to determine the

Table 1 Diet composition for lactating Holstein dairy cattle used for experiment

\section{Composition}

Ingredients, \% of DM

Alfalfa hay

Haylage

Corn silage

Alfalfa green chop

Millrun

Corn (steam flaked)

Barley

Amino plus

Corn distillers grain

Whole cottonseeds

Maxxer

Molasses (cane)

Corn gluten feed

Mineral and vitamin mix

Chemical composition

$\mathrm{NE}_{\mathrm{L}}, \mathrm{Mcal} / \mathrm{lb}$ of DM

$\mathrm{CP}, \%$ of $\mathrm{DM}$

ADF, $\%$ of DM

NDF, \% of DM

Ash, $\%$ of DM

Fat, $\%$ of DM

$\mathrm{Ca}, \%$ of DM

$\mathrm{P}, \%$ of DM

$\mathrm{Mg}, \%$ of DM

$\mathrm{S}, \%$ of DM

$\mathrm{K}, \%$ of DM

$\mathrm{Na}, \%$ of $\mathrm{DM}$

$\mathrm{Cl}, \%$ of DM

Fe, ppm of DM

$\mathrm{Mn}, \mathrm{ppm}$ of DM

$\mathrm{Cu}, \mathrm{ppm}$ of DM

Co, ppm of DM

$\mathrm{Zn}$, ppm of DM
Ammoniated cottonseed

C and Trt

$9 \cdot 24$
$3 \cdot 85$
$11 \cdot 08$
$10 \cdot 15$
$1 \cdot 94$
$16 \cdot 65$
$24 \cdot 01$
$2 \cdot 53$
$4 \cdot 65$
$5 \cdot 74$
$4 \cdot 74$
$2 \cdot 79$
$4 \cdot 33$
$2 \cdot 60$
$2 \cdot 73$

$1 \cdot 62$
$32 \cdot 26$
$33 \cdot 18$
$51 \cdot 32$
$16 \cdot 34$
$11 \cdot 16$
$2 \cdot 10$
$0 \cdot 85$
$0 \cdot 67$
$0 \cdot 53$
$2 \cdot 86$
$1 \cdot 05$
$1 \cdot 41$
$590 \cdot 04$
$153 \cdot 83$
$66 \cdot 90$
$4 \cdot 12$
$134 \cdot 53$

presence of mastitis/inflammation. Milk component analysis was conducted at Arizona DHIA, Tempe, AZ, USA. Milk fat, protein, lactose and solids-non-fat were analyzed using AOAC-approved infrared analysis (AOAC International 2007); somatic cell count (SCC) was done using AOAC-approved cell-staining techniques (AOAC International 2007). The International Dairy Federation and FDA certified all equipment used in the analyses.

All solutions were prepared using sterile-filtered mineral oil mixed with FLX (Sigma), 5-HTP (Sigma) or sterile filtered water as $10 \%$ solutions. FLX was prepared as a $5 \mathrm{mg} / \mathrm{ml}$ solution in water then sterile filtered and stored at $4{ }^{\circ} \mathrm{C}$ for the 4 days of the trial. 5 -HTP was prepared daily in $0.5 \mathrm{M} \mathrm{HCl}$ and then titrated with $10 \mathrm{M} \mathrm{NaOH}$ to a final $\mathrm{pH}$ of $7 \cdot 8$ and stored at $4{ }^{\circ} \mathrm{C}$.

Syringes were prepared using $1 \mathrm{ml}$ sample in a $10 \mathrm{ml}$ syringe and $9 \mathrm{ml}$ mineral oil in a second $10 \mathrm{ml}$ syringe connected to each other using a sterile micro-emulsifying needle (Popper \& Sons, Inc., New Hyde Park, NY, USA). Samples were emulsified into a single syringe, which was 
capped, covered with foil and stored at room temperature until use. Sixty-two doses of each treatment were prepared daily and were mixed within $24 \mathrm{~h}$ of use.

\section{Immunofluorescent imaging}

pBMEC cultured on permeable membranes (Transwell, Corning) were removed from cell culture dishes for immunostaining $48 \mathrm{~h}$ after the initiation of treatment and were fixed on slides by a $20 \mathrm{~min}$ incubation in $4 \%$ paraformaldehyde, then rinsed and stored in sterile PBS at $4{ }^{\circ} \mathrm{C}$. Sections of permeable membranes were permeabilized in $0 \cdot 1 \%$ Triton $\mathrm{X}-100$ and underwent antigen retrieval in borate buffer with $\mathrm{pH}=8.5(80 \mathrm{mM}$ boric acid and $20 \mathrm{mM}$ sodium borate) overnight at $75{ }^{\circ} \mathrm{C}$. Sections were then blocked with immunofluorescent-blocking buffer $(130 \mathrm{mM}$ $\mathrm{NaCl}, 7 \mathrm{mM} \mathrm{Na}_{2} \mathrm{HPO}_{4}, 3 \cdot 5 \mathrm{mM} \mathrm{NaH} \mathrm{PO}_{4}, 0 \cdot 05 \% \mathrm{NaN}_{3}$, $0 \cdot 2 \%$ Triton X-100, $0 \cdot 05 \%$ Tween-20 and $0 \cdot 1 \%$ BSA) for $1.5 \mathrm{~h}$ at room temperature. Sections were incubated with primary antibody (1:50, mouse anti-human, chicken, bovine, zona occludens 1 (ZO-1), Invitrogen) for $75 \mathrm{~min}$ at room temperature and with secondary antibody $(1: 1000$, goat anti-mouse Alexa Fluor 488 Fab fragments; Invitrogen) for $45 \mathrm{~min}$ at room temperature. TOPRO-3 (Invitrogen) was used as the nuclear stain following manufacturer's instructions. Images were obtained using a Zeiss LSM510 NLO Two-Photon Microscope (Zeiss, Thornwood, NY, USA). Images were collected in both the $x-y$ and $x-z$ planes of the permeable membranes.

\section{Quantitative real-time reverse transcription-PCR}

Total RNA from pBMEC lactogenic cultures was isolated using Tri-Reagent per manufacturer's instructions (Molecular Research Center, Cincinnati, OH, USA). The integrity of the RNA was determined using a u.v./visible spectrophotometer (Ultraspec 3100 pro, Amersham Biosciences). For pBMEC isolated from three animals, two wells of a 24-well culture plate were pooled to represent one sample for RNA extraction, with $n=4 /$ treatment. In a given experiment, each treatment was represented in each culture plate, for a total of four culture plates/experiment. The Quanti-Tect Reverse Transcription kit (Qiagen) was utilized for cDNA synthesis from purified mRNA, per manufacturer's instructions.

Quantitative real-time reverse transcription-PCR (qPCR) was conducted with the Step One Plus Real-Time PCR Detection System (Applied Biosystems, Foster City, CA, USA) using fast SYBR green master mix (Applied Biosystems) for the bovine milk protein genes $\alpha$-lactalbumin and $\beta$-casein (Hernandez et al. 2009) per manufacturer's instructions. Ribosomal S15 served as the housekeeping gene (forward primer 5'-CGCGACATGATCATTCTAAA-3', reverse primer $5^{\prime}$-TTACTTGAGGGGGATGAAGC-3'). Analysis of gene expression was conducted using the $2^{-\Delta \Delta C_{\mathrm{t}}}$ method (Livak \& Schmittgen 2001). Gene expression was quantified relative to the control (lactogenic complex + gel release) in a respective sample. All primers met criteria for analysis by the $2^{-\Delta \Delta C_{\mathrm{t}}}$ method, with efficiencies between 95 and 105\% (Livak $\&$ Schmittgen 2001). Amplicons were sequenced prior to use in quantitative real-time PCR assays.

\section{Plasma FLX assay}

Plasma was collected from animals via tail venipuncture and was processed for analysis of FLX levels using a FLX ELISA (Neogen Corporation, Lexington, KY, USA), which measures the competition between FLX and its metabolite (norfluoxetine) for antibody-binding sites. Assay was performed per manufacturer's instructions.

\section{Plasma lactose assay}

Plasma collected from animals via tail venipuncture was processed and analyzed for lactose, using an enzymatic assay that measures the conversion of lactose into galactose and glucose via the enzyme lactase (Biovision, Mountain View, CA, USA). Assay was performed per manufacturer's instructions.

$\mathrm{Na}^{+}$and $\mathrm{K}^{+}$analysis of milk

Milk samples collected from animals on the study were analyzed for $\mathrm{Na}^{+}$and $\mathrm{K}^{+}$content using a digital dual-flame photometer (Cole Parmer Instrument Company, Vernon Hills, IL, USA). Samples were initially diluted in a $3 \mathrm{M}$ lithium solution and $160 \mathrm{mmol} \mathrm{Na}^{+}$and $\mathrm{K}^{+}$solutions were utilized as internal standards.

\section{Data analysis}

Data analysis was conducted using Prism for Macintosh, version $5 \cdot 0 \mathrm{~b}$ for in vitro experiments (GraphPad Software, San Diego, CA, USA). Statistical analysis of TEER in TJ cultures was performed using a one-way ANOVA, with a Tukey's post-hoc test on percent change in TEER relative to control samples. Statistical analysis of qPCR data was conducted using gene expression relative to the control (lactogenic media + gel release) in a respective sample using a one-way ANOVA with a Tukey's post-hoc test. Graphical representation of the data is represented by expression of treatments relative to the lactogenic control $\left(2^{-\Delta \Delta C_{\mathrm{t}}}\right)$. The $\Delta \Delta C_{\mathrm{t}}$ was calculated as $\Delta C_{\mathrm{t}}$ of a respective treatment $-\Delta C_{\mathrm{t}}$ of the control.

Data from the in vivo experiment were analyzed using ANOVA procedures of SAS (SAS Inst., Cary, NC, USA). Milk yields (recorded during the acclimation period and prior to treatments) were analyzed using the PROC MIXED procedure with repeated measures, and included as a covariate in the analysis with a Tukey-Kramer post-test and compound symmetry as the covariance structure. The treatment $X$ day interaction was not significant $(P=0 \cdot 64)$, allowing day and treatment effects to be reported independently. Dependent variables tested were milk yield, milk composition, milk $\mathrm{Na}^{+}$ and $\mathrm{K}^{+}$, plasma lactose, plasma FLX, core body temperature 


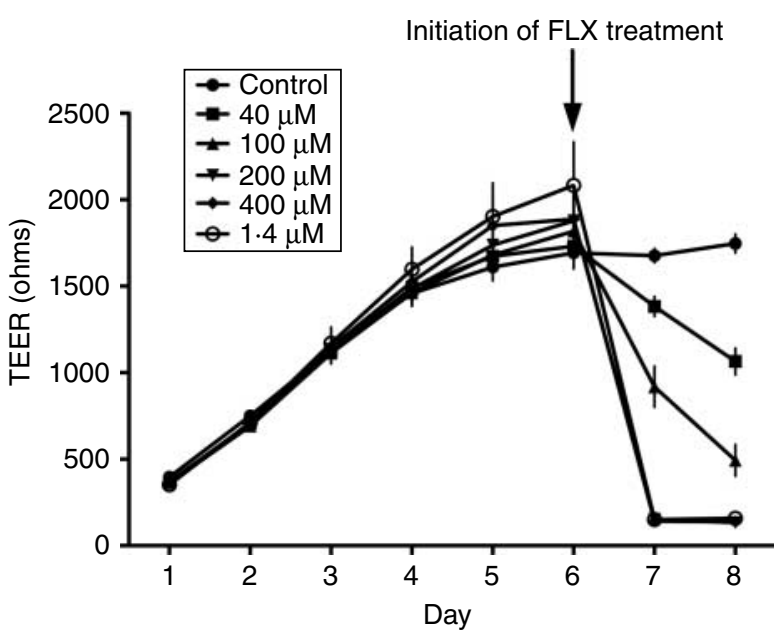

Figure 1 Barrier disruption of pBMEC treated with FLX. Changes of TEER $\left(\Omega \mathrm{cm}^{2}\right)$ in pBMEC treated with $\operatorname{FLX}(40,100,200,400 \mu \mathrm{M}$ and $1.4 \mathrm{mM}$ ) beginning after TEER measurement on day 6 for $24 \mathrm{~h}$ (day 7 ) and $48 \mathrm{~h}$, (day 8). Data are represented as mean \pm s.E.M. The treatments resulted in significant, concentration- and time-dependent, decreases in TEER after 24 and $48 \mathrm{~h}(P<0 \cdot 0001)$

and udder surface temperature. The independent variables included treatment, day, parity and the respective interactions. The level of significance was set at $P<0.05$ for all main effects and interactions and the LSMEANS test was conducted when significance was detected.

\section{Results}

FLX treatment distupted barrier function in $p B M E C$ transwell cultures

pBMEC were cultured on permeable membranes in serumcontaining medium for 6 days prior to reaching plateau
TEER $\left(\sim 2500 \Omega \mathrm{cm}^{2}\right)$. Thereafter, they were treated with various concentrations of FLX for $48 \mathrm{~h}$ with the treatments being applied on the apical side exclusively (Fig. 1). Immunostaining confirmed that SERT was present on the apical membrane of pBMEC (Fig. 2), as was demonstrated previously in human mammary epithelial cells (Stull et al. 2007). FLX treatment of pBMEC resulted in a concentrationdependent decrease in TEER at 24 and $48 \mathrm{~h}$ (Fig. 1). This is in contrast to the biphasic response typically seen in human mammary epithelial cells cultured on selectively permeable membranes (Marshall et al. 2010). The $400 \mu \mathrm{M}$ and $1.4 \mathrm{mM}$ concentrations decreased TEER to a baseline level of $\sim 100 \Omega \mathrm{cm}^{2}$ after $24 \mathrm{~h}$ of treatment $(P<0 \cdot 0001)$.

Immunofluorescent staining for the $\mathrm{TJ}$ protein $\mathrm{ZO}-1$ was conducted on $\mathrm{pBMEC}$ treated with various concentrations of FLX for $48 \mathrm{~h}$. Treatment with 40 and $100 \mu \mathrm{M}$ FLX resulted in a decreased intensity of ZO-1 staining compared with the untreated control, but did not completely extinguish ZO-1 (Fig. 2A and B). However, at $200 \mu \mathrm{M}, \mathrm{ZO}-1$ staining was not detectable after $48 \mathrm{~h}$ of treatment (Fig. 2C). Furthermore, cells treated with higher concentrations of FLX for $48 \mathrm{~h}$ displayed a loss of cells and fragmented nuclei, as visualized by TOPRO-3 staining, indicating cell death (Fig. 2D).

\section{FLX decreased milk protein gene expression in pBMEC lactogenic cultures}

3D collagen gel cultures of pBMEC treated with a serum-free lactogenic hormone complex in combination with gel release have been extensively used to model stage I lactogenesis (McGrath 1987, Hernandez et al. 2008, 2009, Stiening et al. 2008). FLX treatment resulted in a concentration-dependent decrease in $\boldsymbol{\alpha}$-lactalbumin mRNA expression relative to the lactogenic control in lactogenic pBMEC cultures $(P<0 \cdot 0001 ;$ Fig. 3A). Exogenous FLX treatment of lactogenic pBMEC cultures resulted in a biphasic effect on
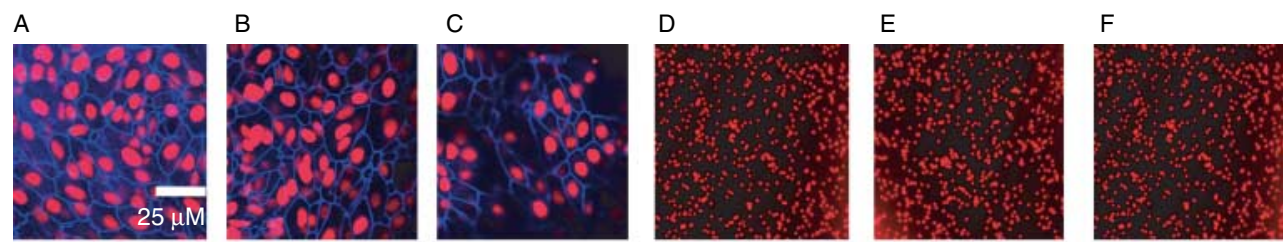

G

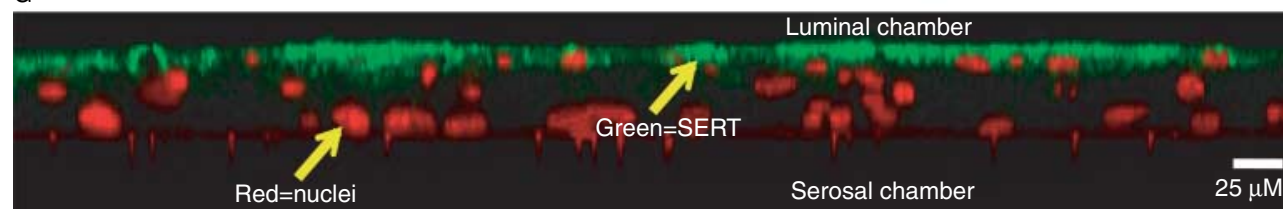

Figure 2 Effects of FLX treatment on the TJ protein, ZO-1. (A-F) Immunostaining of the ZO-1 protein (blue) and nuclei (red) in primary bovine mammary epithelial cells (pBMEC) cultured on permeable membranes treated with a range of FLX (A) Control, (B) 40, (C) 100 and (D) 200, (E) $400 \mu \mathrm{M}$ and (F) $1.4 \mathrm{mM}$ for $48 \mathrm{~h}$. All images were taken at $40 \times$ objective magnification using a Zeiss LSM510 NLO Two-Photon Microscope (Zeiss, Thornwood, NY, USA). (G) Immunostaining for SERT (green) and nuclei (red) in untreated pBMEC cultured on permeable membranes after 10 days in culture, taken as cross section in an $x-z$ plane. Immunostaining indicates the presence of SERT on the apical membrane of pBMEC. 

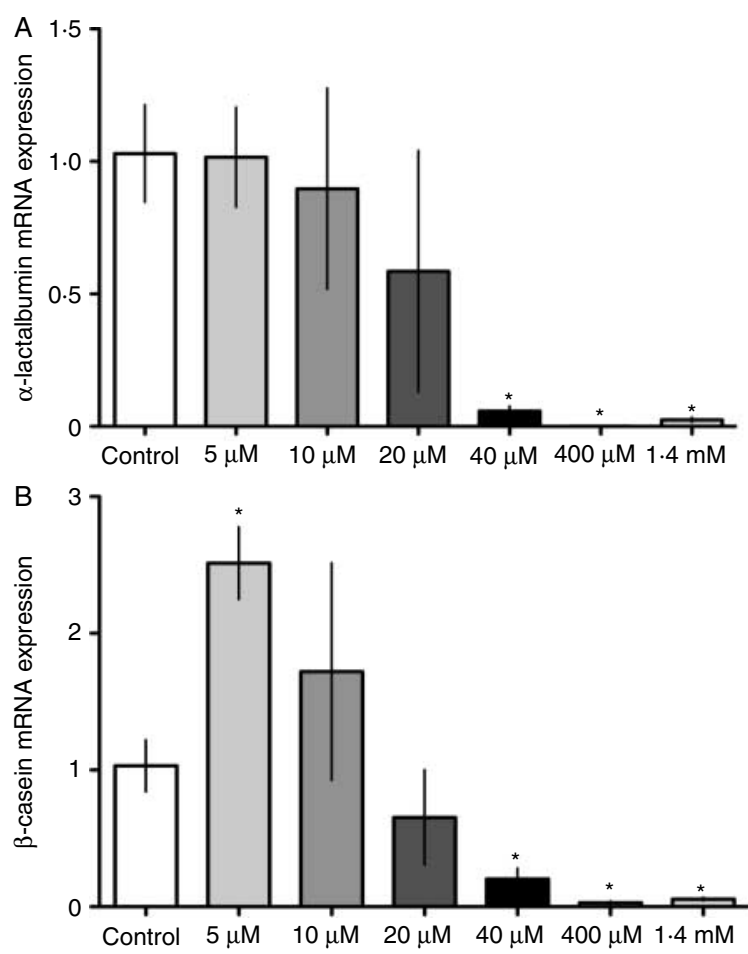

Figure 3 Effects of FLX treatment on milk protein mRNA expression in pBMEC. Mean and S.E.M. of (A) $\alpha$-lactalbumin and (B) $\beta$-casein mRNA expression relative to lactogenic control in $\mathrm{pBMEC}$ treated with a concentration range of FLX $(5 \mu \mathrm{M}-1 \cdot 4 \mathrm{mM})$ plotted as mRNA expression relative to lactogenic control; significance is represented by the following: ${ }^{*} P<0 \cdot 05$.

$\beta$-casein mRNA expression, with increased expression at low concentrations relative to the lactogenic control $(P<0 \cdot 05$; Fig. 3B) while alternatively decreasing expression $\sim 90 \%$ compared with the lactogenic control at high concentrations $(P<0 \cdot 001$; Fig. 3B $)$.

Intramammary infusion of FLX increased TJ permeability and decreased milk yield in Holstein cows

Multiparous Holstein cows that were milked three times daily and were producing at least $20 \mathrm{~kg}$ of milk/day were assigned to the study. As an indicator of TJ status, milk $\mathrm{Na}^{+}$and $\mathrm{K}^{+}$ concentrations and plasma lactose were measured (Stelwagen et al. 1999). The milk $\mathrm{Na}^{+}: \mathrm{K}^{+}$ratio was increased to $2 \cdot 44$ in FLX-treated animals versus 1.44 in control animals in the $48 \mathrm{~h}$ samples $(P<0 \cdot 01$; Fig. $4 \mathrm{~A})$. While there was no significant change in the milk $\mathrm{Na}^{+}: \mathrm{K}^{+}$ratio in the $24 \mathrm{~h}$ samples after FLX treatment, it is important to note that the composition of milk collected from the udder cistern primarily reflects milk that was secreted earlier and accumulated in the udder. In contrast, plasma lactose is an immediate indicator of TJ status. Plasma lactose concentrations were increased 2-fold in FLX-infused animals by $24 \mathrm{~h}$ post-treatment initiation $(P<0 \cdot 0001)$, and remained elevated at $48 \mathrm{~h}\left(P<0 \cdot 05\right.$, Fig. 4B). The increase in the milk $\mathrm{Na}^{+}: \mathrm{K}^{+}$ ratio and the increase in plasma lactose levels in FLX-treated animals support the hypothesis that one aspect of 5-HT activity leads to opening of TJs. There were no significant changes in TJ status seen in 5-HTP-treated animals (Fig. 4A and B).

Data for milk yield were analyzed by regression, with each animal serving as its own control. This approach allowed us the maximum power to detect changes over time within each group. However, for the sake of clarity, the data are represented graphically as group means and errors, rather than as individual animals (Fig. 5). The treatment effect on milk yield was highly significant by regression analysis $(P<0 \cdot 01)$. At $24 \mathrm{~h}$ treatment, FLX-treated cows exhibited the greatest average decline in milk yield (nearly $11 \mathrm{~kg}$ ) compared with those treated with 5-HTP $(8.6 \mathrm{~kg})$ or controls $(7.5 \mathrm{~kg} ; P<0 \cdot 05)$. Although the decline of milk yield in 5-HTP-treated cows was less rapid than in FLX-treated cows, the regression analysis indicated a significant acceleration in the 5-HTP-treated cows, compared with controls $(P<0 \cdot 05)$. Milk composition was not different among any of the
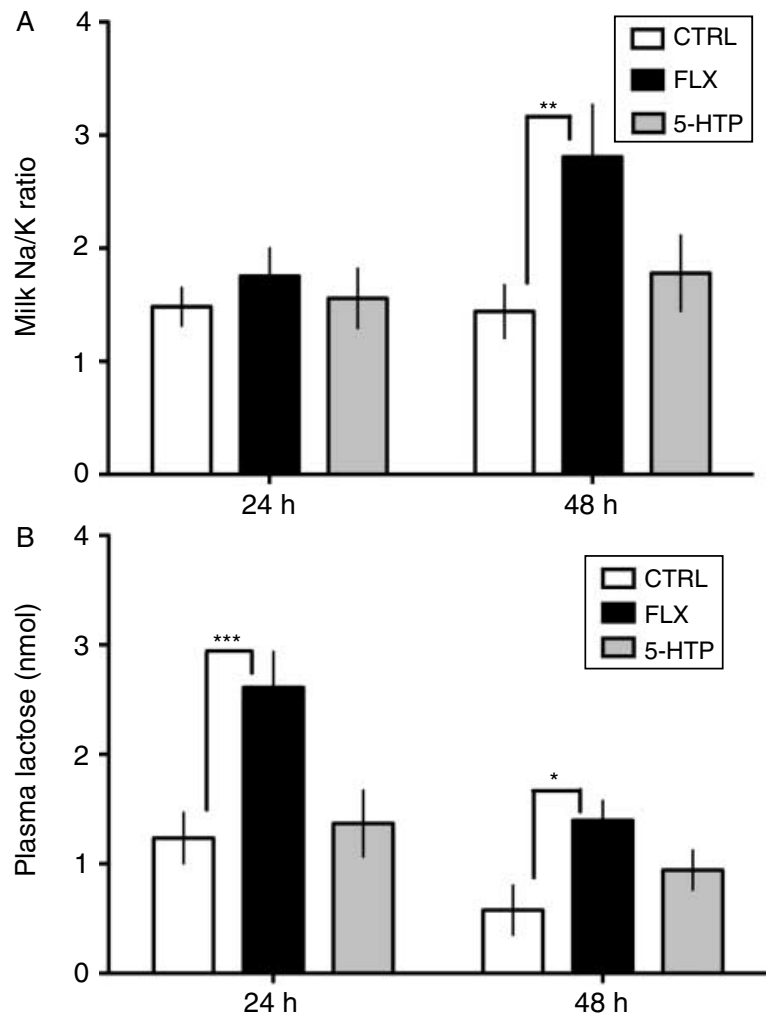

Figure 4 Effects of intramammary infusions of FLX on TJ status in Holstein dairy cows. (A) Mean with S.E.M. of milk Na${ }^{+}: \mathrm{K}^{+}$ratio in milk collected from cows treated for 24 and $48 \mathrm{~h}$ with intramammary infusions of vehicle control (CTRL), $5 \mathrm{mg}$ FLX or $5 \mathrm{mg} 5$-HTP.

Significance is represented by the following: $* * P<0 \cdot 001$. (B) Mean with S.E.M of plasma lactose $(\mathrm{mmol})$ in cows treated with intramammary infusions of CTRL, $5 \mathrm{mg}$ FLX, or $5 \mathrm{mg} 5$-HTP. Significance is represented by the following: ${ }^{*} P<0 \cdot 05,{ }^{* * *} P<0 \cdot 0001$. 


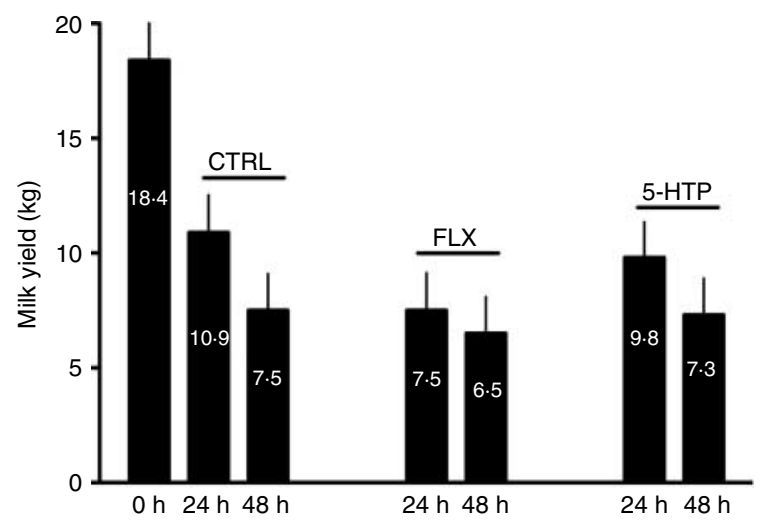

Figure 5 Milk production in Holstein cows treated with intramammary infusion of FLX, 5-HTP or a vehicle control. Milk yield (kg; group means \pm S.E.M.) of Holstein cows treated with intramammary infusions of a vehicle control (CTRL), $5 \mathrm{mg}$ FLX or $5 \mathrm{mg} 5$-HTP. The columns are labeled with the mean value for milk yield $(\mathrm{kg})$ of each group. See text for full description of statistical analysis and inferences.

treatment groups (Table 2). The absence of any increase in SCC indicates that there was no observable inflammatory response to treatments. Plasma FLX concentrations were not increased until 4 days post-infusion in FLX-treated animals only $(2 \cdot 186 \mathrm{vs} 0 \mathrm{ng} / \mathrm{ml} ; P<0 \cdot 0001)$. As indicators of health status, rectal temperatures, udder surface temperatures and respiration rates were measured in all groups. Rectal temperatures were found decreased in animals receiving FLX than in controls and 5-HTP-treated animals $(P<0 \cdot 03$; Table 3). Additionally, udder surface temperatures were decreased in all groups over the treatment interval, as milk yield waned $(P<0 \cdot 001$; Table 3$)$, and was lower in FLXtreated animals compared with controls and 5-HTP-treated cows $(P<0 \cdot 003$; Table 3). Presumably, the decline in udder surface temperature was associated with the decreasing milk synthesis and mammary blood flow, and the absence of elevated rectal or udder temperatures supports the lack of inflammatory responses to the treatments. No significant changes in respiration rates were detected.

\section{Discussion}

5-HT is an autocrine-paracrine signaling molecule, which has recently been demonstrated to accelerate the rate of mammary gland involution and regulate mammary gland homeostasis (Matsuda et al. 2004, Stull et al. 2007, Pai \& Horseman 2008). While a variety of 5-HT receptors in the mammary gland of different species have been identified, the components involved in the synthesis (TPH1) of 5-HT and reuptake into the cell for degradation (SERT) are conserved (Matsuda et al. 2004, Hernandez et al. 2009, Marshall et al. 2010). Inhibition of SERT activity through the use of SSRIs such as FLX modifies endogenous 5-HT activity by increasing the exposure of the cell to endogenous 5-HT. Recently, it was demonstrated that treatment of human mammary epithelial cells with SSRI resulted in effects similar to those seen with exogenous 5-HT treatment (Marshall et al. 2010).

Disruption of TJs in the mammary gland is a hallmark of mammary gland involution. The dynamics of TJs are largely regulated by the cycle of milk accumulation and removal, with $\mathrm{TJ}$ permeability decreasing when milk is frequently removed and TJ permeability increasing during milk stasis (Nguyen \& Neville 1999). Cultures of mammary epithelial cells on permeable membranes (Transwell) provide a reliable, consistent model for the examination of polarized mammary epithelial cells, with the measurement of the electrical conductance across the mammary epithelium (between the apical and basolateral plasma membranes), providing indications of TJ status (Stull et al. 2007, Marshall et al. 2009). Using pBMEC cultured on permeable membranes, we demonstrated that apical treatments of FLX resulted in decreases in TEER within $24 \mathrm{~h}$ of treatment, and that the extent of the decrease in TEER was concentrationdependent. Unlike human mammary epithelial cells, we did not see a biphasic effect of FLX on TEER. Beginning with apical treatments of $100 \mu \mathrm{M}$ FLX, TJs were completely disassembled after $24 \mathrm{~h}$ of treatment as measured by TEER and lack of peripheral immunostaining for ZO-1 (Figs 1 and $2 \mathrm{~A}-\mathrm{D})$. $\mathrm{ZO}-1$ is an adaptor protein required in the

Table 2 Milk composition in Holstein cattle treated with intramammary infusions of fluoxetine (FLX) and 5-hydroxytryptophan (5-HTP). Values displayed are means with S.E.M.

\begin{tabular}{|c|c|c|c|c|c|}
\hline & Fat $(\%)$ & Protein $(\%)$ & Lactose $(\%)$ & SNF $(\%)$ & SCC $($ cells $/ \mathrm{ml})$ \\
\hline \multicolumn{6}{|l|}{$24 \mathrm{~h}$} \\
\hline Control & $4 \cdot 3(0 \cdot 3)$ & $3 \cdot 4(0 \cdot 2)$ & $4 \cdot 0(0 \cdot 2)$ & $8 \cdot 5(0 \cdot 4)$ & $576(206)$ \\
\hline FLX & $4 \cdot 8(0 \cdot 4)$ & $3 \cdot 8(0 \cdot 2)$ & $3 \cdot 7(0 \cdot 2)$ & $8 \cdot 5(0 \cdot 3)$ & $602(242)$ \\
\hline 5-HTP & $3 \cdot 6(0 \cdot 5)$ & $3 \cdot 5(0 \cdot 2)$ & $4 \cdot 4(0 \cdot 3)$ & $8 \cdot 9(0 \cdot 4)$ & 552 (306) \\
\hline \multicolumn{6}{|l|}{$48 \mathrm{~h}$} \\
\hline Control & $3 \cdot 1(0 \cdot 4)$ & $4 \cdot 0(0 \cdot 2)$ & $3 \cdot 7(0 \cdot 2)$ & $8 \cdot 7(0 \cdot 3)$ & 489 (217) \\
\hline FLX & $3 \cdot 5(0 \cdot 4)$ & $3 \cdot 9(0 \cdot 2)$ & $3 \cdot 9(0 \cdot 2)$ & $8 \cdot 8(0 \cdot 3)$ & 612 (216) \\
\hline 5-HTP & $3.9(0.4)$ & $4 \cdot 0(0 \cdot 2)$ & $3 \cdot 8(0 \cdot 2)$ & $8 \cdot 8(0 \cdot 3)$ & 796 (228) \\
\hline \multicolumn{6}{|l|}{$72 \mathrm{~h}$} \\
\hline Control & $5 \cdot 7(0 \cdot 3)$ & $4 \cdot 2(0 \cdot 2)$ & $2 \cdot 8(0 \cdot 2)$ & $8 \cdot 3(0 \cdot 2)$ & 852 (177) \\
\hline FLX & $5 \cdot 2(0 \cdot 3)$ & $3 \cdot 8(0 \cdot 2)$ & $2 \cdot 9(0 \cdot 2)$ & $8 \cdot 3(0 \cdot 2)$ & $1173(190)$ \\
\hline 5-HTP & $5 \cdot 9(0 \cdot 4)$ & $4 \cdot 4(0 \cdot 2)$ & $3 \cdot 3(0 \cdot 2)$ & $8.9(0.3)$ & $657(228)$ \\
\hline
\end{tabular}


Table 3 Health parameters measured in Holstein cattle treated with intramammary infusions of fluoxetine (FLX) and 5-hydroxytryptophan (5-HTP). Values displayed are means (s.E.M.)

\begin{tabular}{|c|c|c|c|}
\hline & $\begin{array}{l}\text { Rectal } \\
\text { temperature }\left({ }^{\circ} \mathrm{C}\right)\end{array}$ & $\begin{array}{l}\text { Udder } \\
\text { temperature }{ }^{+}\left({ }^{\circ} \mathrm{C}\right)\end{array}$ & $\begin{array}{l}\text { Respiration } \\
\quad \text { rate (breaths/min) }\end{array}$ \\
\hline \multicolumn{4}{|l|}{$24 \mathrm{~h}$} \\
\hline Control & $38.7(0 \cdot 14)$ & $29 \cdot 4(0 \cdot 19)$ & $35 \cdot 3(1 \cdot 61)$ \\
\hline FLX & $37 \cdot 8(0 \cdot 33)^{*}$ & $28 \cdot 7(0 \cdot 26)$ & $34 \cdot 6(1 \cdot 08)$ \\
\hline 5-НTP & $38 \cdot 3(0 \cdot 14)$ & $29 \cdot 2(0 \cdot 26)$ & $32 \cdot 8(1 \cdot 18)$ \\
\hline \multicolumn{4}{|l|}{$48 \mathrm{~h}$} \\
\hline Control & $38 \cdot 3(0 \cdot 15)$ & $26 \cdot 6(0 \cdot 31)$ & $32 \cdot 6(0.92)$ \\
\hline FLX & $38 \cdot 2(0 \cdot 14)$ & $26 \cdot 2(0 \cdot 28)$ & $34.0(1.09)$ \\
\hline 5-HTP & $38 \cdot 4(0 \cdot 11)$ & $26 \cdot 5(0 \cdot 31)$ & $34 \cdot 6(1 \cdot 16)$ \\
\hline \multicolumn{4}{|l|}{$72 \mathrm{~h}$} \\
\hline Control & $38 \cdot 3(0 \cdot 10)$ & $24 \cdot 3(0 \cdot 34)$ & $30 \cdot 9(0.98)$ \\
\hline FLX & $38 \cdot 2(0 \cdot 07)$ & $23 \cdot 3(0 \cdot 38)$ & $30 \cdot 1(0 \cdot 95)$ \\
\hline 5-HTP & $38 \cdot 2(0 \cdot 08)$ & $23 \cdot 7(0 \cdot 69)$ & $29 \cdot 5(1 \cdot 24)$ \\
\hline
\end{tabular}

*Rectal temperatures were significantly reduced in FLX-treated animals at $24 \mathrm{~h}$ of treatment $(P<0 \cdot 03)$. ${ }^{+}$Udder temperatures were significantly decreased in all treatments at 48 and $72 \mathrm{~h}$ of treatment $(P<0 \cdot 001)$. FLX-treated animals had significantly lower udder surface temperatures than either 5-HTP or control groups at all time points $(P<0 \cdot 003)$.

assembly of TJs and is a common morphological marker of TJs (Paris et al. 2008). Additionally, as concentrations of FLX were increased, we saw a subsequent decrease in nuclei number, as well as nuclei fragmentation, indicated by TOPRO-3 staining (Fig. 2A-F). Previous reports in human and BMEC demonstrated that FLX disrupted TJs when both the apical and basolateral chambers were treated with the drug (Marshall et al. 2010).

Stage I lactogenesis, or secretory differentiation, begins at mid-pregnancy and involves increased and sustained expression of milk protein genes such as $\beta$-casein and $\boldsymbol{\alpha}$-lactalbumin, as the mammary epithelium differentiates into lactocytes (Pang \& Hartmann 2007). Therefore, we utilized an in vitro model in which to measure the effects of FLX on the milk protein genes $\beta$-casein and $\alpha$-lactalbumin (McGrath 1987, Hernandez et al. 2008, 2009). Upon treating lactogenic $\mathrm{pBMEC}$ cultures with increasing concentrations of FLX, $\beta$-casein mRNA expression responded biphasically, with substantial suppression of expression beginning at $40 \mu \mathrm{M}$ (Fig. 3B). This is in accordance with previous reports in which treatment of human mammary epithelial cells with exogenous 5-HT and FLX resulted in a biphasic effect on TJ permeability, with low concentrations of 5-HT potentiating $\mathrm{TJ}$ formation and high concentrations resulting in disassembly of TJs (Pai \& Horseman 2008, Marshall et al. 2010). There was a concentration-dependent suppression of $\alpha$-lactalbumin (Fig. 3A). $\alpha$-Lactalbumin is the key protein involved in the synthesis of lactose, which is the primary osmolyte for milk secretion (Akers 2002). The ability of FLX to cause concentration-dependent inhibition of key milk protein genes suggests that increased cellular exposure to endogenously synthesized 5-HT will suppress lactation. Previous reports demonstrated that nursing mothers who are also taking SSRI treatment exhibited a delay in the onset of lactogenesis stage II (Marshall et al. 2010). Additionally, it was also determined that lactating mice implanted with FLX pellets in the mammary gland exhibited a rapid local involution of the gland.

Current practices targeting mammary gland involution focus on abrupt cessation of milking in combination with antibiotic therapy to prevent mastitis infections. Previous studies in which FLX pellets implanted in mouse mammary glands resulted in increased rates of mammary gland involution (Marshall et al. 2010). However, pellet implantation is not a practical method that can be utilized for a dryoff treatment in lactating mothers or dairy animals. In order to determine the ability of FLX to disrupt lactation in an in vivo model, we infused FLX directly into the teats of lactating, multiparous Holstein cows at the end of their respective lactation cycles. Additionally, we investigated the effects of 5-HTP, which is an intermediate in the 5-HT synthesis pathway that bypasses the rate-limiting step (Wang et al. 2002) and was also delivered by intramammary infusion. Our hypothesis was that milk yield would decline in all animals with reduced milking stimulus, but this decline would be accelerated in FLX- and 5-HTP-treated animals. Intramammary infusions of FLX resulted in a more rapid decline in milk production $(10.9 \mathrm{~kg}$ decrease by $24 \mathrm{~h})$ than either 5-HTPtreated $(8.6 \mathrm{~kg})$ or control $(7.5 \mathrm{~kg})$ animals. Plasma lactose and the milk $\mathrm{Na}^{+} / \mathrm{K}^{+}$ratio are typical in vivo measurements of TJ status in lactating animals (Stelwagen et al. 1999). Cows treated with intramammary infusions of FLX exhibited disruption of TJs, as indicated by increases in plasma lactose (24 and $48 \mathrm{~h}$ after initiation of FLX treatment) and the milk $\mathrm{Na}^{+} / \mathrm{K}^{+}$ratio $(48 \mathrm{~h})$. We did not see increases in the milk $\mathrm{Na}^{+} / \mathrm{K}^{+}$ratio by $24 \mathrm{~h}$, presumably because the bulk of the milk collected from the udder cisterns had been synthesized much earlier. Intramammary infusions of 5-HTP modestly 
increased the rate of milk decline $(P<0 \cdot 05)$ at the dose used here. However, it did not cause measurable changes in $\mathrm{TJ}$ status. Future experiments should be conducted with higher doses of 5-HTP. Cows receiving the FLX treatment also displayed decreased udder and rectal temperatures compared with 5-HTP-treated and CTRL animals, although all animals exhibited decreased udder temperatures upon treatment, indicating reduced metabolism and/or blood flow and the lack of inflammatory responses. There were no increases in SCC after treatments, further indicating the lack of inflammatory responses (Table 2). The ability of FLX, and to a lesser extent 5-HTP, to accelerate the involution process in dairy animals entering the dry period could be important in preventing future mammary gland infections, either along with, or instead of, currently used methods (i.e. antibiotic treatments). Currently, treatments that rapidly terminate lactation in the dairy cattle are not in practice despite previous reports that acceleration of the involution decreases incidence of mastitis (Oliver \& Smith 1982, Gulay et al. 2009).

The ability of an SSRI to increase the activity of 5-HT in the lactating mammary gland has recently been examined. Our data indicate that apical treatment of pBMEC cultured on permeable membranes with FLX disrupts TEER and ZO1 staining in vitro. Furthermore, we demonstrate that FLX treatment decreases milk protein gene expression in a concentration-dependent manner in a serum-free lactogenic model, and finally, that intramammary infusions in vivo result in a greater decline in milk yield in Holstein cows. The implications of the ability of FLX to accelerate mammary gland involution will be of great importance to improving the health of animals entering the dry period portion of their respective lactation cycles. Future studies should be directed at determining the optimum conditions (i.e. concentrations, combination therapies with 5-HTP and/or antibiotics) for the use of FLX as a tool to manipulate mammary gland involution in vivo.

\section{Declaration of interest}

LLH, RJC and NDH declare interests in intellectual property related to this work. RJC and NDH declare interests in commercialization of related technologies through Amelgo, LLC.

\section{Funding}

This project was supported by Agriculture and Food Research Initiative Competitive Grant no. 2009-35206-05178 from the USDA National Institute of Food and Agriculture, Animal Growth and Nutrient Utilization Program. L L H was supported by a CURE fellowship from the National Cancer Institute.

\section{Acknowledgements}

The authors thank Arcadia University Faculty Development Funds for support of A J V.

\section{References}

Akers RM 2002 Lactation and the Mammary Gland. Ames, IA: Iowa State Press, Blackwell Publishing Professional.

AOAC International 2007 Official methods of analysis $18^{\text {th }} \mathrm{ed}$. Horwitz W \& Latimer G (eds). Association of Official Analytical Chemists International, Arlington, VA.

Barbey JT \& Roose SP 1998 SSRI safety in overdose. Journal of Clinical Psychiatry 59 (Supplement 15) 42-48.

Betzold CM 2007 An update on the recognition and management of lactation breast inflammation. Journal of Midwifery and Women's Health 52 595-605. (doi:10.1016/j.jmwh.2007.08.002)

Bradley AJ \& Green MJ 2000 A study of the incidence and significance of intramammary enterobacterial infections acquired during the dry period. Journal of Dairy Science 83 1957-1965. (doi:10.3168/jds.S0022-0302(00) 75072-7)

Capuco AV \& Akers RM 1999 Mammary involution in dairy animals. Journal of Mammary Gland Biology and Neoplasia 4 137-144. (doi:10.1023/ A:1018769022990)

Collier RJ, Annen EL \& Fitzgerald AC 2004 Prospect for zero days dry. Veterinary Clinics of North America. Food Animal Practice 20 687-701. (doi:10. 1016/j.cvfa.2004.06.009)

Dingwell RT, Kelton DF, Leslie KE \& Edge VL 2001 Deciding to dry-off: does level of production matter? National Mastitis Council Annual Proceedings, pp 69-79.

Dingwell RT, Duffield TF, Leslie KE, Keefe GP, DesCoteaux L, Kelton DF, Lissemore KD, Schukken YH, Dick P \& Bagg R 2002 The efficacy of intramammary tilmicosin at drying-off and other risk factors for the prevention of new intramammary infections during the dry period. Journal of Dairy Science 85 3250-3259. (doi:10.3168/jds.S0022-0302(02) 74413-5)

Eberhart RJ 1986 Management of dry cows to reduce mastitis. Journal of Dairy Science 69 1721-1732. (doi:10.3168/jds.S0022-0302(86)80591-4)

Gulay MS, Hayen MJ, Head HH \& Bachman KC 2009 Short communication: effect of estrogen supplementation at dry-off on temporal changes in concentrations of lactose in blood plasma of Holstein cows. Journal of Dairy Science 92 3815-3818. (doi:10.3168/jds.2009-2032)

Hernandez LL, Stiening CM, Wheelock JB, Baumgard LH, Parkhurst AM \& Collier RJ 2008 Evaluation of serotonin as a feedback inhibitor of lactation in the bovine. Journal of Dairy Science 91 1834-1844. (doi:10.3168/jds. 2007-0766)

Hernandez LL, Limesand SW, Collier JL, Horseman ND \& Collier RJ 2009 The bovine mammary gland expresses multiple functional isoforms of serotonin receptors. Journal of Endocrinology 203 123-131. (doi:10.1677/JOE-09-0187)

Livak KJ \& Schmittgen TD 2001 Analysis of relative gene expression data using real-time quantitative PR and the $2^{-\Delta \Delta C_{\mathrm{t}}}$ method. Methods $\mathbf{2 5}$ 402-408. (doi:10.1006/meth.2001.1262)

Marshall AM, Pai VP, Sartor MA \& Horseman ND 2009 In vivo multipotent differentiation and barrier function of a human mammary epithelium. Cell and Tissue Research 335 383-395. (doi:10.1007/s00441-008-0719-0)

Marshall AM, Nomsen-Rivers LA, Hernandez LL, Dewey KG, Chantry CJ, Gregerson KA \& Horseman ND 2010 Serotonin transport and metabolism in the mammary gland modulates secretory activation and involution. Journal of Clinical Endocrinology and Metabolism 95 837-846. (doi:10.1210/jc. 2009-1575)

Matsuda M, Imaoka T, Vomachka AJ, Gudelsky GA, Hou Z, Mistry M, Bailey JP, Nieport KM, Walther DJ, Bader M et al. 2004 Serotonin regulates mammary gland development via an autocrine-paracrine loop. Developmental Cell 6 193-203. (doi:10.1016/S1534-5807(04)00022-X)

McGrath MF 1987 A novel system for mammary epithelial cell culture. Journal of Dairy Science 70 1967-1980. (doi:10.3168/jds.S0022-0302(87) 80239-4)

Michie Q, Lockie F \& Lynn W 2003 The challenge of mastitis. Archives of Disease in Childhood 88 818-821. (doi:10.1136/adc.88.9.818)

Nguyen DD \& Neville MC 1999 Tight junction regulation in the mammary gland. Journal of Mammary Gland Biology and Neoplasia 3 233-246. (doi:10.1023/A:1018707309361) 
Oliver SP \& Smith KL 1982 Nonantibiotic approach in control of bovine mastitis during dry period. Journal of Dairy Science 65 2119-2124. (doi:10. 3168/jds.S0022-0302(82)82470-3)

Oliver SP \& Sordillo LM 1988 Udder health in the periparturient period. Journal of Dairy Science 71 2584-2606. (doi:10.3168/jds.S0022-0302(88) 79847-1)

Pai VP \& Horseman ND 2008 Biphasic regulation of mammary epithelial resistance by serotonin through activation of multiple pathways. Journal of Biological Chemistry 283 30901-30910. (doi:10.1074/jbc.M802476200)

Pai VP, Marshall AM, Hernandez LL, Buckley AR \& Horseman ND 2009 Altered serotonin physiology in human breast cancers favors paradoxical growth and cell survival. Breast Cancer Research 11 R81. (doi:10.1186/ bcr2448)

Paris L, Tonutti L, Vannini C \& Bazzoni G 2008 Structural organization of tight junctions. Biochimica et Biophysica Acta 1778 646-659. (doi:10.1016/ j.bbamem.2007.08.004)

Rainard P 2005 Tackling mastitis in dairy cows. Nature Biotechnology 23 430-432. (doi:10.1038/nbt0405-430)

Stein T, Salomonis N \& Gusterson BA 2007 Mammary gland involution as a multi-step process. Journal of Mammary Gland Biology and Neoplasia 12 25-35. (doi:10.1007/s10911-007-9035-7)

Stelwagen K, Farr VC \& McFadden HA 1999 Alteration of the sodium potassium ration in milk and the effect on milk secretion in goats. Journal of Dairy Science 82 52-59. (doi:10.3168/jds.S0022-0302(99)75208-2)
Stiening CM, Hoying JB, Abdallah MB, Hoying AM, Padney R, Greer K \& Collier RJ 2008 The effects of endocrine and mechanical stimulation on stage I lactogenesis in bovine mammary epithelial cells. Journal of Dairy Science 91 1053-1066. (doi:10.3168/jds.2007-0161)

Stull MA, Pai V, Vomachka AJ, Marshall AM, Jacob GA \& Horseman ND 2007 Mammary gland homeostasis employs serotonergic regulation of epithelial tight junctions. PNAS 104 16708-16718. (doi:10.1073/pnas. 0708136104)

Thomas KLH \& Ellingrod VE 2009 Pharmacogenetics of selective serotonin reuptake inhibitors and associated adverse drug reactions. Pharmacotherapy 29 822-883. (doi:10.1592/phco.29.7.822)

Wang L, Erlandsen H, Haavik J, Knapskog PM \& Stevens RC 2002 Three-dimensional structure of human tryptophan hydroxylase and its implications for the biosynthesis of the neurotransmitters serotonin and melatonin. Biochemistry 41 12569-12574. (doi:10.1021/bi026561f)

\section{Received in final form 29 January 2011 \\ Accepted 9 February 2011 \\ Made available online as an Accepted Preprint \\ 9 February 2011}

